\title{
The effect of conical flowfields on the performance of waveriders at Mach 6
}

\author{
CUI Kai ${ }^{1,2 \dagger}$ \& YANG GuoWei ${ }^{1}$ \\ ${ }^{1}$ Key Laboratory of High Temperature Gas Dynamics, Institute of Mechanics, Chinese Academy of Sciences, Beijing 100080, China; \\ ${ }^{2}$ State Key Laboratory of Structural Analysis for Industrial Equipment, Dalian University of Technology, Dalian 116023, China
}

The performance of $\mathbf{2 3}$ kinds of waveriders, derived from different conical flowfields, is analyzed by the numerical computation under the conditions of fight speed of Mach 6 , attack angle of $0^{\circ}$ and flight altitude of $30 \mathrm{~km}$. These results indicate that the performance is influenced by the shapes and the width to height ratios $(W / H)$ of generating cones. The geometrical parameter and the lift coefficient are proportional to $W I H$, while the drag coefficient and the lift to drag ratio (LID) have extreme values. Considering the base drag and the computation errors, the waverider with the highest $L I D$ is cut from the elliptical cone's flowfield $(W I H=1.5-1.618)$, and the configuration with the lowest drag can also be obtained at $W I H=1: 1.5$. Accordingly, good suggestions are proposed for practical design based on these computational results.

hypersonic vehicle, waverider, computational fluid dynamics

The general rule of thumb is that the hypersonic regime begins at above Mach 5. As we know, hypersonic flows have several properties, such as thin shock layer, strong entropy gradients and thick boundary layer, etc. These phenomena can interact with each other and produce many complications in vehicle design, e.g., the shock layer may merge with the boundary layer to form a fully viscous shock layer. These complications will lead to heavy wave drag and skin friction of the vehicle, and form a lift to drag ratio $(L / D)$ barrier $^{[1]}$. Therefore, it is difficult to get a high aerodynamic performance for a hypersonic vehicle with general configurations.

Nowadays, one of the most competitive candidate configurations is waverider. The waverider is a type of hypersonic lifting body, introduced by Nonweiler in $1959^{[2]}$. When it flies at its designed Mach number, the entire bow shock will attach to the leading edge (LE) of the body. Since there is no flow spillage from the lower surface to the upper surface, the high pressure behind the shock wave will lead to a high lift. The vehicle seems to ride on top of the attached shock wave when flying at its designed Mach number, so it is dubbed the "waverider".

At present, there are two main methods of the waverider designs: the flowfield derived method and the osculating cone method. The osculating cone method was proposed by Sobieczky ${ }^{[3,4]}$. On the basis of the strip theory, the configuration is a shock-based solution that defines the flowfield directly from a specified shockwave and allows the direct selection of scramjet's inlet flowfield while providing good volumetric and packaging. This method has been studied and developed by many researchers owing to its flexibility and simplicity, but the osculating cone waverider might not be exact due to the effects of the crossflow were neglected. Lewis et al. ${ }^{[5]}$ developed pressure gradient correction method to get the exact configuration to some extent.

The other branch of waverider design is the flowfield derived method, by which a waverider can be cut from a

\footnotetext{
Received September 4, 2006; accepted December 4, 2006 doi: 10.1007/s11434-007-0026-2

${ }^{\dagger}$ Corresponding author (email: kcui@imech.ac.cn)

Supported by the National Natural Science Foundation of China (Grant Nos. 10502053 and 10402043), the Key Laboratory of High Temperature Gas Dynamics of Chinese Academy of Sciences, and the State Key Laboratory of Structural Analysis for Industrial Equipment of Dalian University of Technology
} 
known flowfield. In the first instance, Nonweiler ${ }^{[2]}$ generated a class of vehicles with a caret-shaped cross section and a delta planform by choosing the flowfield behind a planar oblique shock wave. Similarly, Jones ${ }^{[6]}$ and Rasmussen et al. ${ }^{[7-9]}$ designed other configurations based on the hypersonic small-disturbance theory. In their works, the cone, the inclined cone and the elliptic cone were chosen as generating bodies, respectively. Subsequently, more complicated flow fields were used to generate waveriders by the aid of computational fluid dynamics (CFD) with the development of computers and numerical techniques. For example, Mazhul et al. ${ }^{[10]}$ designed axisymmetric power-law shapes to get higher $L / D$ waverider forms than those cone-derived ones; Takashima and Lewis ${ }^{[11]}$ constructed the waveriders in the cone-wedged flowfield. Recently, Goonko et al. ${ }^{[12]}$ presented the convergent-flow-derived waveriders, which were derived from the supersonic or hypersonic axisymmetric flows inside constricting ducts. In order to extend the design space, we developed a flexible method based on CFD analysis ${ }^{[13]}$, in which a waverider can be derived from any conical flowfields.

The geometrical and aerodynamic performance of different flowfield-derived configurations may be different. The motivation of our work is to explore the relationship between the different flowfields and their derived waveriders. In this paper, we analyzed 23 kinds of waveriders' performance under the conditions of fight speed of Mach 6, attack angle of $0^{\circ}$ and flight altitude of $30 \mathrm{~km}$. It was found that the performance was influenced by the shapes and the width to height ratios $(W / H)$ of generating cones. The waverider with the highest $L / D$ was cut from the elliptical cone's flowfield $(W / H=1.5-1.618)$, and the configuration with the lowest drag was obtained at $W / H=1: 1.5$.

\section{The waverider design procedure}

The general procedure of designing a waverider configuration is sketched in Figure 1. To begin with, the inviscid hypersonic flowfield around a predefined body is computed with CFD analysis under the design condition. The shock wave layer can also be captured from the obtained flowfield simultaneously. Next, a LE, which should be located on the shock exactly, is specified to define a waverider. Afterward, the lower surface of the waverider is constructed by tracing the streamline originated from the given LE, while the upper surface is usually created by simply following the freestream through the LE to the base of the waverider. Since there is no flow normal to the stream surface, the flowfield around the waverider can be taken as the part of the original one. Besides the above designed work, the CFD analysis is often carried on in order to evaluate the performances of the configuration.

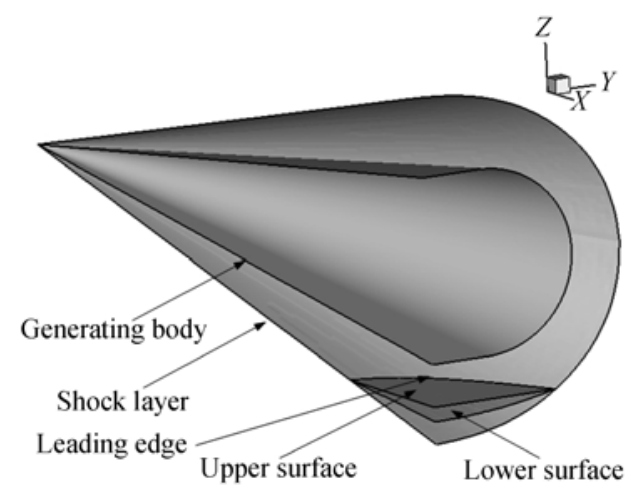

Figure 1 A general sketch of a designed waverider.

\subsection{Inviscid flowfield computation}

The generating bodies are arbitrary cones without longitudinal curvature. The cross sections of them are defined by the flexible B-spline curves as

$$
\begin{aligned}
P(t) & =\frac{1}{6}\left[\begin{array}{llll}
t^{3} & t^{2} & t & 1
\end{array}\right]\left[\begin{array}{cccc}
-1 & 3 & -3 & 1 \\
3 & -6 & 3 & 0 \\
-3 & 0 & 3 & 0 \\
1 & 4 & 1 & 0
\end{array}\right]\left[\begin{array}{l}
P_{0} \\
P_{1} \\
P_{2} \\
P_{3}
\end{array}\right], \\
P(t) & =(x(t), y(t)), t \in[0,1], \\
P_{i} & =\left(X_{i}, Y_{i}\right),(i=0, \ldots, 3),
\end{aligned}
$$

where $P_{0}, P_{1}, P_{2}$ and $P_{3}$ are control points. The shape of the curve $P(t)$ varies with these control points relatively.

The inviscid flowfield around the conical body was computed by solving the Euler equations numerically. A structural grid with the $C-H$ topology was used to discretize the computational domain. In order to achieve a precise shock resolution, a solution-based adaptive grid was employed. In other words, an estimated position of the shock layer was taken as the clustered region of the grids initially. After several iterations, the regions of a high pressure gradient were captured as the shock layer, and the grid was allowed to recluster there. Generally, the adaptive operation is repeated for several times until the thickness of the captured shock layer is thin enough.

\subsection{Definition of the leading edge}

Once the flowfield and the shock are obtained, a wa- 
verider can be defined by an LE uniquely. Because the 3D LE must be located on the shock, it can be determined by its projection at the base plane. Moreover, it is convenient for the $2 \mathrm{D}$ curve to use parameterized functions. In this paper, the linear function, the quadric function and the sigmoid function were invoked.

\subsection{The lower and the upper surface design}

The waverider's lower surface is generated from a streamsurface (composed of streamlines) behind the shock layer. The streamlines is depicted by the following equation:

$$
\frac{\mathrm{d} x}{u}=\frac{\mathrm{d} y}{v}=\frac{\mathrm{d} z}{w}=\mathrm{d} s,
$$

in which, $u, v$ and $w$ are the velocity components in three axes. Eq. (1) is an ordinary differential function; it can be solved by the classic Runge-Kutta method easily. The upper surface of the waverider is created by simply following the freestream back through the given LE to the base of the waverider.

\subsection{The CFD analysis tools}

To evaluate the aerodynamic performance of a waverider, a 3D thin-layer Reynolds-averaged Navier-Stokes equations solver in strong conservation law form was employed. In this program, the LU-SGS method of Yoon and Jameson ${ }^{[14]}$ with employing a Newton-like sub-iteration was used. The inviscid terms were approximated by modified third-order upwind HLLEW scheme of Obayashi et al. ${ }^{[15]}$. For the isentropic flow, the scheme results in the standard upwind-biased flux-difference splitting scheme of Roe, and as the jump in entropy became large in the flow, the scheme turned to a standard HLLEW scheme. Thin-layer viscous term in equations was discretized by second-order central difference, while the Baldwin-Lomax model was adopted to simulate the turbulent effect.

The grid used for this study was an H-type structural multiblock grid. The whole computational domain was divided into ten blocks. The grids near the wall and near the shock layer were refined to improve the computational accuracy.

\section{Numerical results and analysis}

\subsection{Conical body}

Tweenty-three conical bodies with different cross sections were selected. The length of them is 100 (dimensionless). The basic conical angle (in the $X Z$ plane) was $7.09^{\circ}$ except for the star conical body. Another important parameter is the $W / H$, which is defined by the ratio of the width (at $Y$ axis) over the height (at $Z$ axis) of a body.

All bodies and their cross sections are shown in Figures $2-5$. Totally twenty elliptic cones, five quadrate cones, two elliptic-quadrate cones, two crisscross cones, one floriated cone and one starlike cone are included. The $W / H$ of part bodies are shown in Table 1 , the other $W / H$ values are 1.

\subsection{Definition of the waveriders}

Once the flowfield and the shock are calculated, a waverider is defined uniquely by the LE. To ensure the comparability of various waveriders, a similar definition method is employed to create all configurations, as shown in Figure 6. The lowest point of the shock is taken as the baseline. The projections of all LE are 5 units from the baseline upwards.
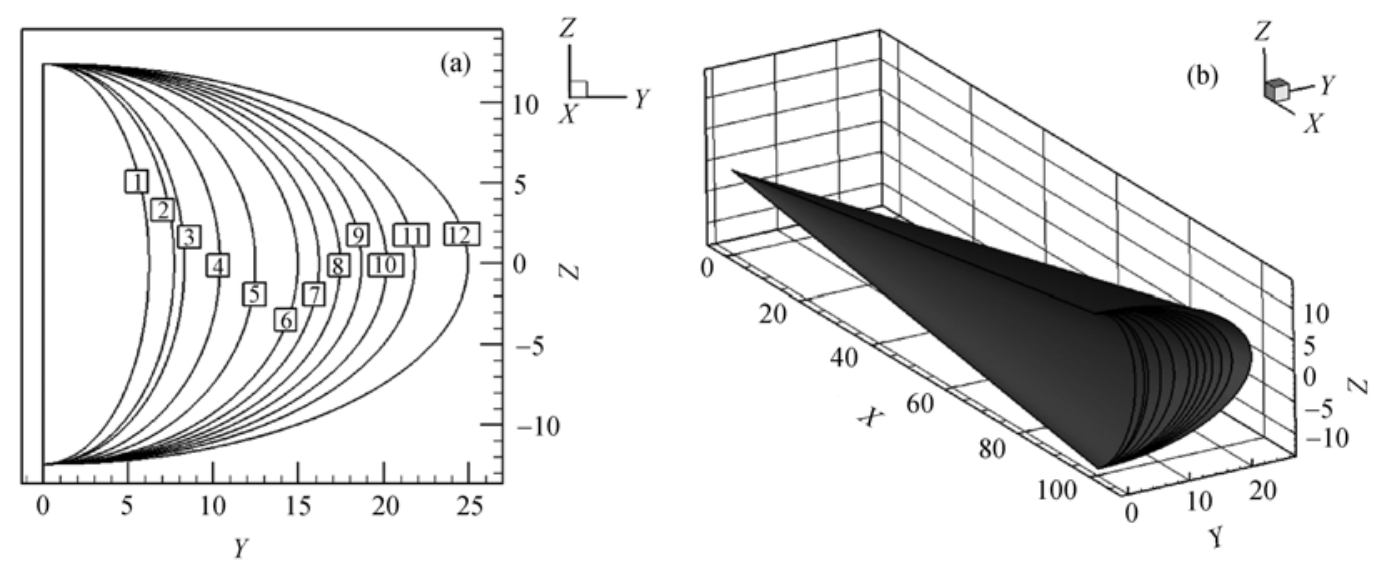

Figure 2 The cross section (a) and the 3D shape of the elliptic cones (b), respectively. 

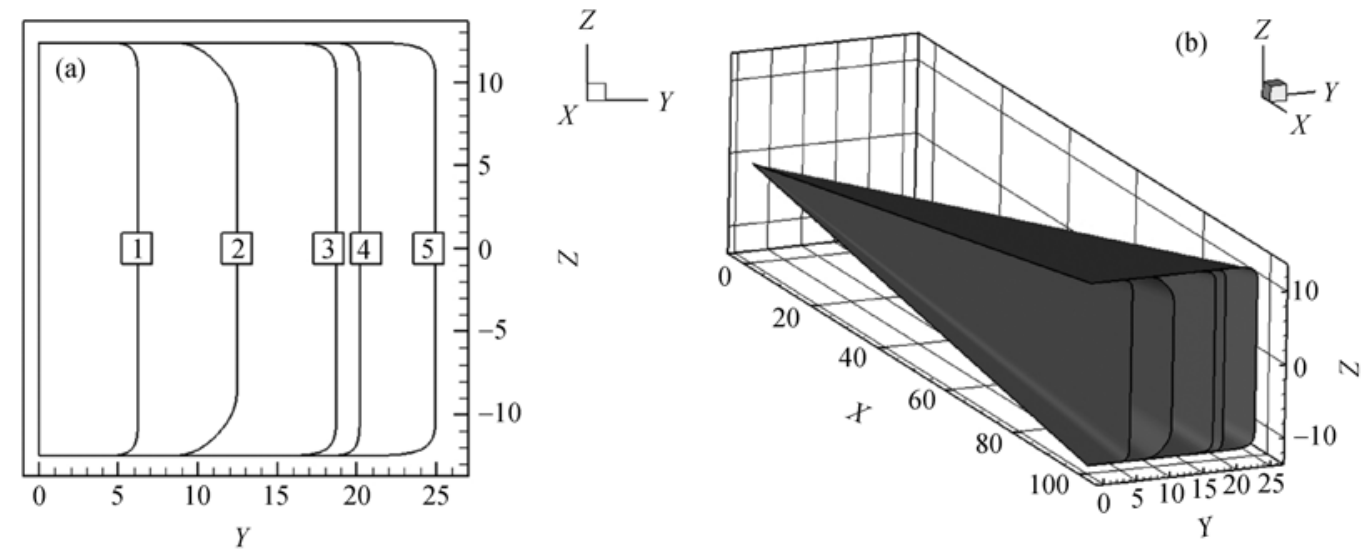

Figure 3 The cross section (a) and the 3D shape of the quadrate cones (b), respectively.
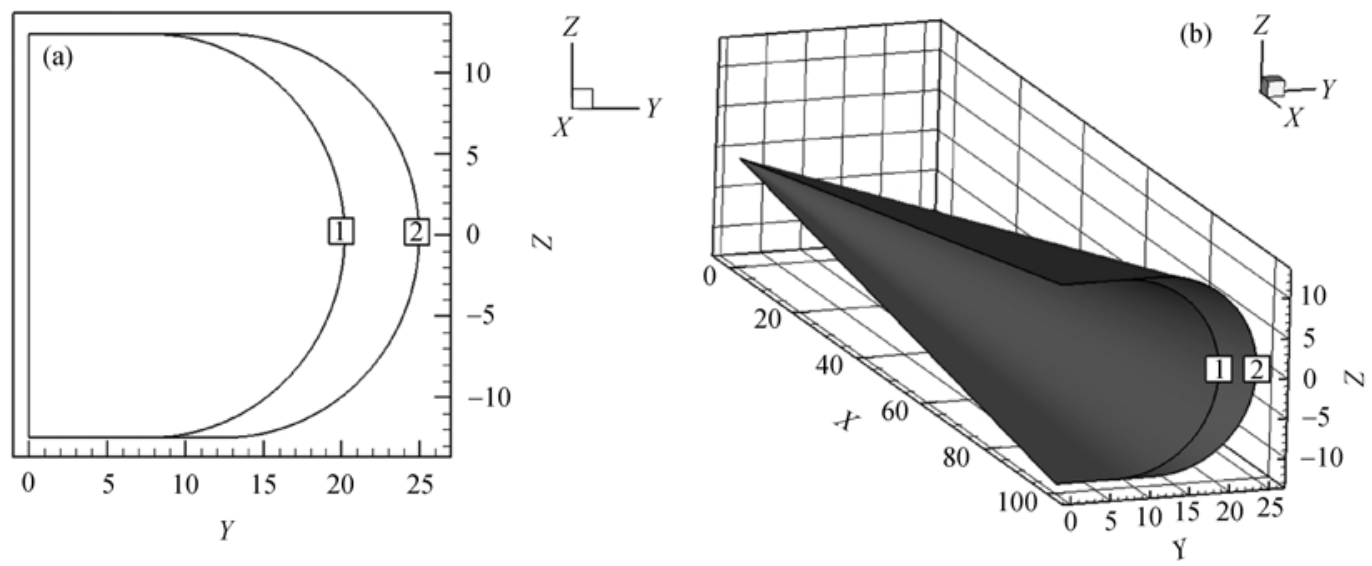

Figure 4 The cross section (a) and the 3D shape of the elliptic-quadrate cones (b), respectively.

(a)

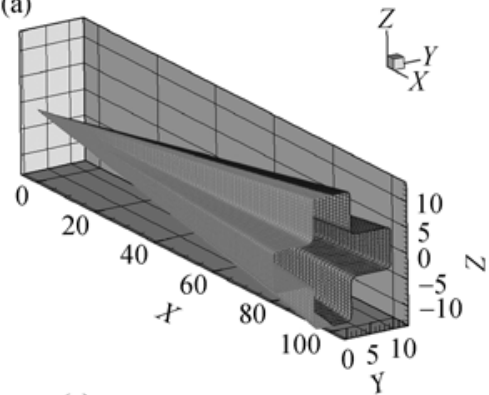

(c)

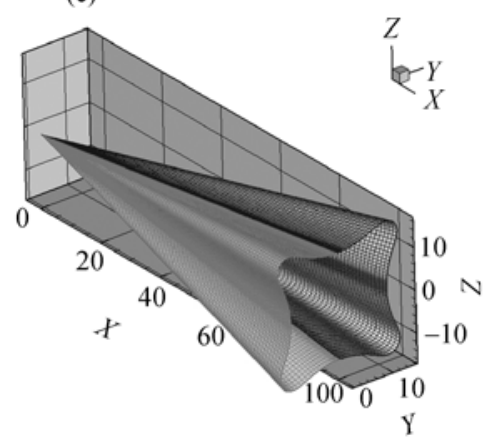

(b)

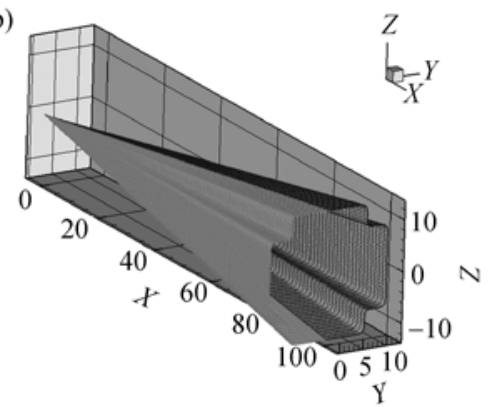

(d)

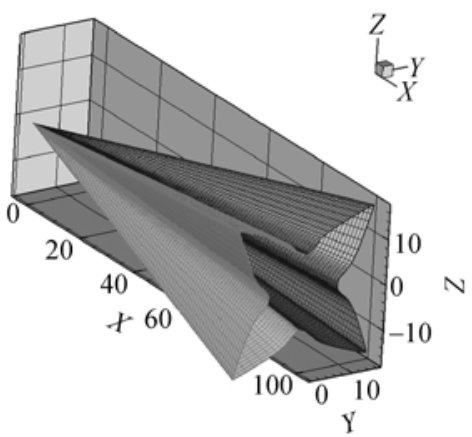

Figure 5 (a) 3D shape of the thin crisscross cone; ( b) 3D shape of the thick crisscross cone, (c) 3D shape of the floriated cone; (d) 3D shape of the starlike cone. 
Table 1 The $W / H$ values of the cones

\begin{tabular}{lcccccc}
\hline Case & 1 & 2 & 3 & 4 & 5 & 6 \\
\hline Elliptic & 0.5 & 0.618 & 0.6667 & 0.8333 & 1 & 1.2 \\
Quadrate & 0.5 & 1 & 1.5 & 1.618 & 2 & - \\
Ellptic-quadrate & 1.618 & 2 & - & - & - & - \\
\hline \hline Case & 7 & 8 & 9 & 10 & 11 & 12 \\
Elliptic & 1.3 & 1.4 & 1.5 & 1.618 & 1.75 & 2 \\
\hline
\end{tabular}

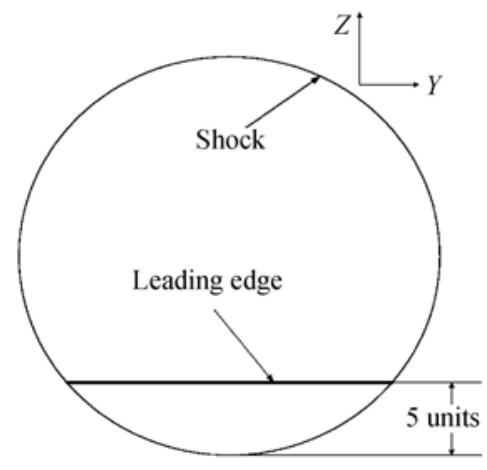

Figure 6 Leading edge definition.

\subsection{Computational conditions}

The computational conditions are shown in Table 2. An example of the grid structure is shown in Figure 7. The grid number of each block and the height of the first layer are shown in Table 3.

\subsection{Comparisons of the geometrical parameters}

Comparisons of the geometrical parameter, included the cubage, the total surface area, the projection area, the wingspan and the thickness at the centerline were made for all configurations. The results are shown in Figure 8.

The following rules can be found according to Figure 8. First, different cone-derived waveriders lead to different geometrical parameters. Second, the geometrical parameters of the floriated or the starlike cone derived waveriders are comparatively large. In contrast, when the thin crisscross cone is chosen as the generating body, the geometrical parameters of the corresponding waverider are small. In addition, the thinner the cone petal,

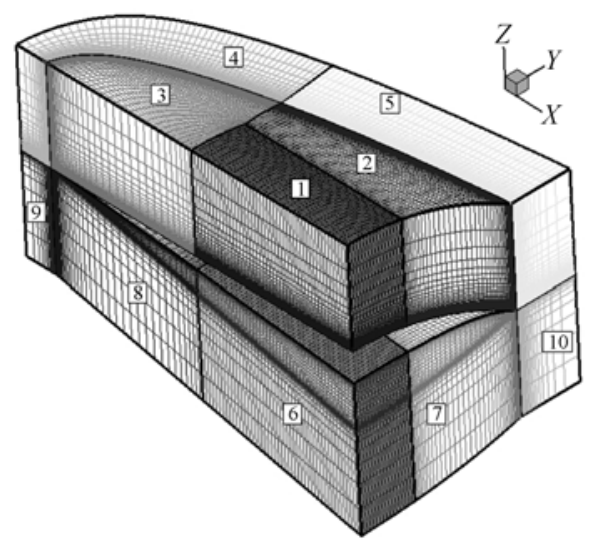

Figure 7 Example of grid structure.

the smaller the geometrical parameters. Finally, the geometrical parameters are directly proportional to the $W / H$ of the cones if the generating cones belong to a same family.

\subsection{Comparisons of the aerodynamic parameters}

The lift coefficient, the drag coefficient and the $L / D$ are shown in Figure 9. The base area is taken as the ref- erence area and the base pressure of all computation cases is equal to zero.

We can learn from Figure 9:

(1) Lift and drag coefficients of the floriated cone derived configuration are maximal with the same $W / H$ values of generating cones. On the contrary, the minimal values of the two coefficients are obtained from crisscross cone flowfield.

(2) To the elliptic cone derived waveriders, when the $W / H$ of the generating body is $1: 1.5$, the minimal value of the drag coefficient appeared. As to the other configurations, we do not ensure the existence and the position of the minimal drag, and it relies on the further analysis.

(3) The $L / D$ of the thin crisscross derived waverider is comparatively small. If the $W / H$ is equal to 1 , there is no evident difference between the $L / D$ of the configurations derived from different cones. As to the elliptic cone

Table 2 Computational conditions

\begin{tabular}{ccccc}
\hline Length $(\mathrm{m})$ & Altitude $(\mathrm{km})$ & Velocity $($ Mach) & Attack angle $\left({ }^{\circ}\right)$ & Reynolds number \\
\hline 3 & 30 & 6 & 0 & 7000000 \\
\hline
\end{tabular}

Table 3 Data related to grids

\begin{tabular}{ccccc}
\hline Block index & Grid number of $I$ direction & Grid number of $J$ direction & Grid number of $K$ direction & Height of the first layer \\
\hline $1,2,3,6,7,8$ & 49 & 49 & 49 & 0.0001 \\
$4,5,9,10$ & 31 & 49 & 49 & 0.0001 \\
\hline
\end{tabular}



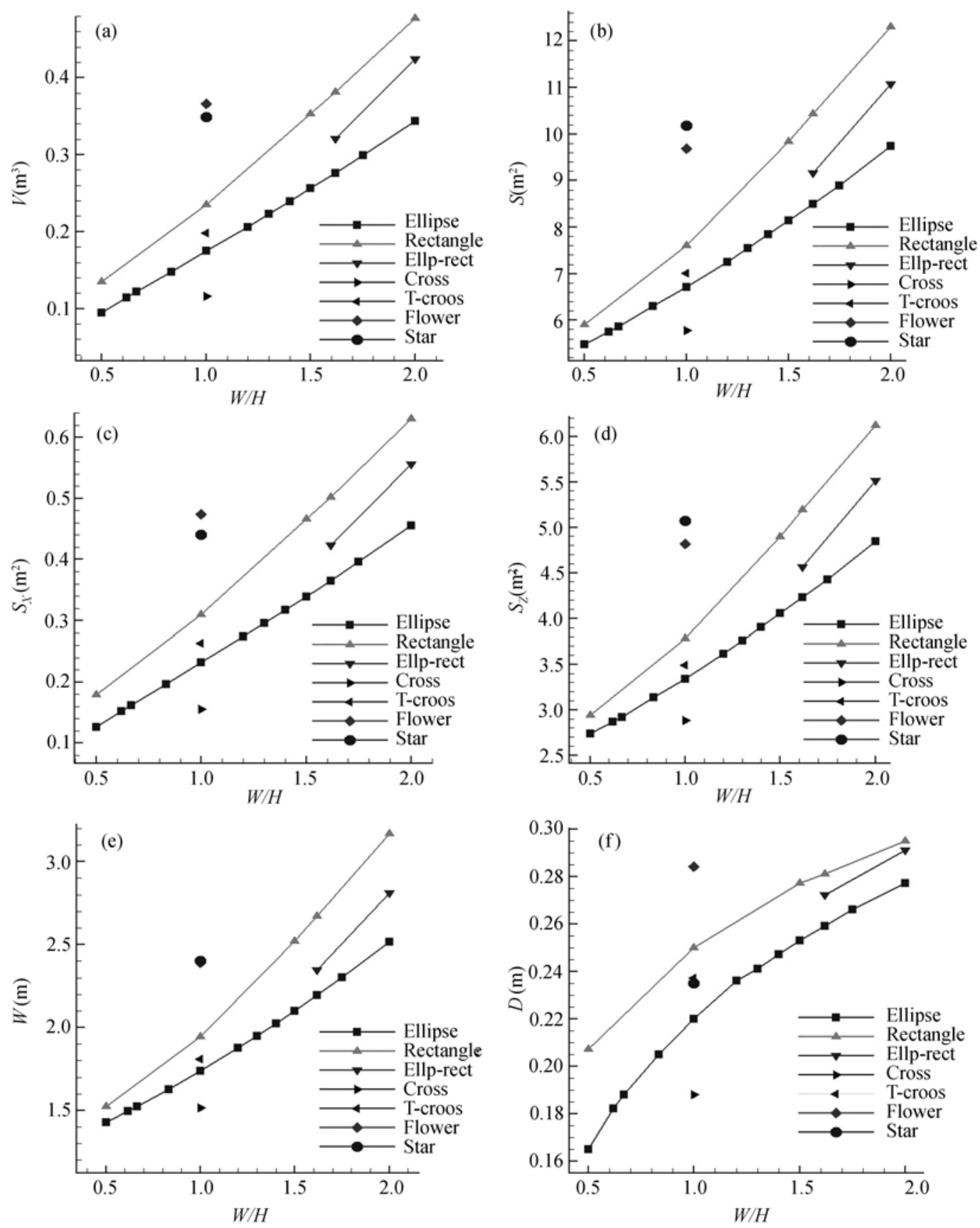

Figure 8 Geometrical parameters comparisons of different waveriders. (a) Half of cubage; (b) half of total surface area; (c) half of projection area in $X$ direction; (d) half of projection area in $Z$ direction; (e) half of Wingspan; (f) thickness at the centerline. Ellipse, rectangle, ellp-rect, corss, T-cross, flower and star denote the elliptic, quadrate, elliptic-quadrate, thin crisscross, thick crisscross, floriated and starlike cone derived waverders, respectively.

derived waveriders, the maximal value of the $L / D$ appeared when the $W / H$ of the generating body is 1.618 . Furthermore, if the $W / H$ varies around this position, the variance of the $L / D$ is not obvious. Considering the computational errors, the waverider configuration with the maximal $L / D$ can be obtained when the $W / H$ of the generating elliptic cone is around $1.5-1.618$.

\section{Further validation}

In the above computation, the projections of the LE in the $Y Z$ plane are all lines. Another two definition methods for the LE are adopted in order to further validate the above conclusions. To save the computational time, three of the above cones are chosen arbitrarily, where the 

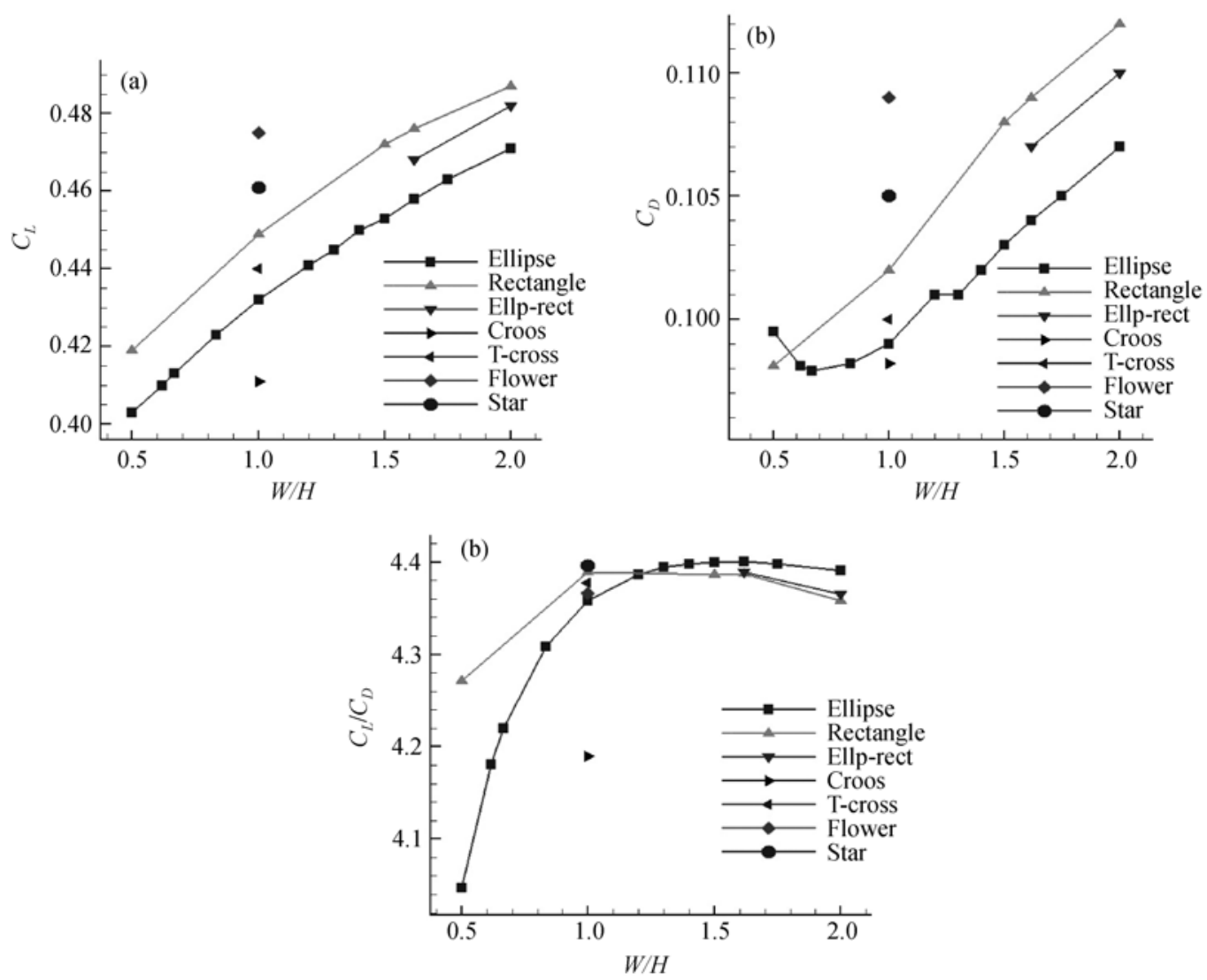

Figure 9 Comparison of the aerodynamic parameters. (a) Comparison of the lift; (b) comparison of the drag; (c) comparison of the $L / D$. The base pressure $P_{\text {base }}=0$.

cross sections of the cones are the circle, the square and the thin crisscross, respectively.

\subsection{The quadric leading edge}

In the first validation case, the projection of the LE in the $Y Z$ plane is defined as follows:

$$
Z=Z_{\text {sw }}+Z_{0}+A y^{2}
$$

where $Z_{s w}$ denotes the lowest point of the shock layer in $Z$ direction, $Z_{0}$ and $A$ are adjustable parameters. Here, $Z_{0}$ is 10 and $A$ is 0.05 . The geometrical and the aerodynamic parameters of the corresponding configurations are listed in Tables 4 and 5. In Table 4, $V$ denotes the cubage of the waveriders, $S$ denotes the area of total surface, $S_{X}$ denotes the projection area in $X$ direction, $S_{Z}$ denotes the projection area in $Z$ direction, $W$ denotes the wingspan, and $T$ denotes the thickness at the center position. In Table 5, $C_{L}$ and $C_{D}$ denote the lift and the drag coefficient.

\subsection{The sigmoid leading edge}

In this case, the projection of the LE in the $Y Z$ plane is defined as the following sigmoid function:
Table 4 The geometrical parameters of the quadric LE waveriders

\begin{tabular}{ccccccc}
\hline Case & $V\left(\mathrm{~m}^{3}\right)$ & $S\left(\mathrm{~m}^{2}\right)$ & $S_{x}\left(\mathrm{~m}^{2}\right)$ & $S_{z}\left(\mathrm{~m}^{2}\right)$ & $W(\mathrm{~m})$ & $T(\mathrm{~m})$ \\
\hline Circle & 0.0783 & 3.02 & 0.102 & 1.41 & 0.734 & 0.259 \\
Square & 0.0982 & 3.27 & 0.127 & 1.52 & 0.788 & 0.282 \\
Thin cross & 0.0565 & 2.75 & 0.0741 & 1.28 & 0.673 & 0.242 \\
\hline
\end{tabular}

Table 5 The aerodynamic parameters of the quadric LE waveriders

\begin{tabular}{cccc}
\hline Case & $C_{L}$ & $C_{D}$ & $L / D$ \\
\hline Circle & 0.4678 & 0.1039 & 4.5029 \\
Square & 0.4831 & 0.1069 & 4.5173 \\
Thin cross & 0.4505 & 0.1033 & 4.3597 \\
\hline
\end{tabular}

$$
Z=Z_{s w}+Z_{0}+\frac{1}{1+e^{\left(y-Y_{0}\right)}}
$$

where $Z_{s w}$ denotes the lowest point of the shock layer in $Z$ direction, $Z_{0}$ and $Y_{0}$ are adjustable parameters. Here, $Z_{0}$ is 7 and $Y_{0}$ is 5 . The geometrical and the aerodynamic parameters of the corresponding configurations are listed in Tables 6 and 7.

The symbols in Tables 6 and 7 are the same as the corresponding ones in Tables 4 and 5. By comparing the above results with Figures 8 and 9, we can find that the 
Table 6 The geometrical parameters of the sigmoid LE waveriders

\begin{tabular}{lcccccc}
\hline Case & $V\left(\mathrm{~m}^{3}\right)$ & $S\left(\mathrm{~m}^{2}\right)$ & $S_{x}\left(\mathrm{~m}^{2}\right)$ & $S_{z}\left(\mathrm{~m}^{2}\right)$ & $W(\mathrm{~m})$ & $T(\mathrm{~m})$ \\
\hline Circle & 0.119 & 4.5228 & 0.164 & 2.2446 & 1.25 & 0.244 \\
Square & 0.157 & 5.0558 & 0.216 & 2.5064 & 1.39 & 0.269 \\
Thin cross & 0.0812 & 3.9338 & 0.111 & 1.9541 & 1.11 & 0.219 \\
\hline
\end{tabular}

Table 7 The aerodynamic parameters of the sigmoid LE waveriders

\begin{tabular}{cccc}
\hline Case & $C_{L}$ & $C_{D}$ & $L / D$ \\
\hline Circle & 0.4338 & 0.1002 & 4.3271 \\
Square & 0.4514 & 0.1039 & 4.3432 \\
Thin cross & 0.4141 & 0.0991 & 4.1771 \\
\hline
\end{tabular}

results listed in Tables $4-7$ are consistent with the above rules for the geometrical and aerodynamic parameters.

\section{Conclusions}

In this paper, the geometrical and aerodynamic parameters of 23 waverider configurations derived from different generating cones were analyzed and compared by CFD analysis. A primary rule was obtained based on these results. Moreover, it is obvious that there is a contradiction between the geometrical and aerodynamic performance. It will lead to a reduction in the other performance no matter what performance is chased one-sided. This contradiction implies that it may be impossible to design a "perfect" configuration with the best aerodynamic and geometrical performance simultaneously. A more important thing maybe is how to balance

1 Kuchemann D. The Aerodynamic Design of Aircraft. Oxford: Pergamon Press, 1978. 448-510

2 Nonweiler T R F. Aerodynamic problems of manned space vehicles. J Roy Aeronaut Soc, 1959, 63: 521-528

3 Jones K D, Sobieczky H, Seebass A R, et al. Waverider design for generalized shock geometries. J Spacecraft Rockets, 1995, 32(6): 957-963.

4 Timothy F, Brien O, Lewis M J. Rocket-based combined-cycle engine integration on an osculating cone waverider vehicle. J Aircraft, 2001, 38(6): 1117-1123

5 Lewis M J, Chauffour M L. Shock-based waverider design with pressure gradient corrections and computational simulations. J Aircraft, 2005, 42(5): 1350-1352

6 Jones J G, Moore K C, Pike J, et al. A method for designing lifting configurations for high supersonic speeds using axisymmetric flowfields. Ing Arch, 1968, 37: 56-72

7 Rasmussen M L. Waverider configurations derived from inclined circular and elliptic cones. J Spacecraft Rockets, 1980, 17(5): 537—545

8 Rasmussen M L. On hypersonic flow past an unyawed cones. AIAA J, the two aspects for a practical configuration.

For practical designs, the main performance index that should be pursued may also be different due to the different species and purposes. On the basis of the above results, we think that the elliptical cone derived waveriders are preferable for a general hypersonic vehicle configuration. Especially, when the $W / H$ of the generating elliptic cone is $1: 1.5$ and $1.5-1.618$, the minimal drag configuration and the maximal $L / D$ configuration can be obtained. Besides, the following recommendations for practical design of the hypersonic vehicles can be presented. Although the aerodynamic performance should be considered for a hypersonic aerobus, the main object is to pursue the largest cubage of the vehicle, while the performance in subsonic or supersonic regime should also be considered. Therefore, the configuration derived from a floriated cone with a high $\mathrm{W} / \mathrm{H}$ is preferable, which can offer the large cubage and wingspan. On the other hand, the crisscross cone derived waveriders should be a prior consideration if the stealth performance is the key issue, where a small cross area of the vehicle is required. In addition, the thinner the crisscross petal is chosen, the better the stealth performance can be obtained.

Finally, it should be noted that the conclusions in this paper are only validated at Mach 6 . We believe that similar rules may exist at other Mach number. Indeed, this inference should be proved by a great deal of numerical and experimental works, which are under way.

1967, 5: 1495-1497

9 Doty R T, Rasmussen M L. Approximation for hypersonic flow past an inclined cone. AIAA J, 1973, 11: 1310-1315

10 Mazhul I I, Rakhimov R D. Hypersonic power-law shaped waveriders in off-design regimes. J Aircraft, 2004, 41(4): 839-845

11 Takashima N, Lewis M J. Optimization of waverider-based hypersonic cruise vehicles with off-design considerations. J Aircraft, 1999, 36(1): $235-245$

12 Goonko Y P, Mazhul I I, Markelov G. N. Convergent-flow-derived waveriders. J Aircraft, 2000, 37(4): 647-654

13 Yoon S, Jameson A. Lower-upper symmetric-gauss-seidel method for the Euler and Navier-Stokes equations. AIAA J, 1988, 26(9): 10251026

14 Cui K, Yang G W. A CFD-based waverider design method for any conical geometry. In: Proceeding of East West High Speed Flowfield Conference. Beijing, 2005. 475-480

15 Obayashi S, Guruswamy G P. Convergence acceleration of a Navier-Stokes solver for efficient static aeroelastic computations. AIAA J, 1995, 33(6): 1134-1141 